\title{
Moeda, Ciclo e Incerteza Fundamental em Hayek*
}

\section{Money, Business Cycle and Fundamental Uncertainty in Hayek}

\author{
André Roncaglia de Carvalho** \\ Eduardo Angeli***
}

Resumo: O objetivo do artigo é investigar de que maneira a teoria monetária e dos ciclos de F. A. Hayek deixa implícita a admissão, por este autor, da existência do tipo de incerteza classificado como fundamental. Para isso é feita uma breve exposição das variedades de incerteza segundo classificação de Dequech em alguns de seus trabalhos. Em seguida, passa-se à exposição da visão hayekiana acerca do papel central da moeda e do crédito na determinação do ciclo econômico, da existência do mecanismo da poupança forçada e a real possibilidade de falsificação da taxa de juros e de que o sistema econômico atue fora do equilíbrio. A partir daí se abre o caminho para que o sistema de preços não forneça as informações necessárias à correta formação de expectativas e à tomada de decisão por parte dos agentes, característica central da incerteza fundamental.

Palavras-chave: F. A. Hayek. Incerteza. Ciclos econômicos.

Abstract: The article aims at investigating how F. A. Hayek's monetary and business cycle theory implicitly assumes the existence of fundamental uncertainty. In order to achieve such a goal, the authors make a short exposition of the concept of fundamental uncertainty as defined by Dequech in several of his works. Afterwards, the authors expose the Hayekian interpretation on the central role of money and credit on business cycle, on the mechanism of forced saving and on the possibility of falsification of interest rate and the possibility of the economic system to behave away from the equilibrium. It can be said, then, that the price system may not supply the agents with the information that is necessary for the formation of correct expectations and decisions, a key characteristic of fundamental uncertainty.

Keywords: F. A. Hayek. Uncertainty. Business cycles.

JEL Classification: B31; D83; E32; E49.

\footnotetext{
* Versão anterior deste artigo está nos anais do XII Encontro de Economia da Região Sul (Maringá, 2009). Os autores agradecem a Fabio Barbieri e aos pareceristas anônimos da Análise Econômica pelas críticas e sugestões, isentando-os, contudo, dos erros e omissões remanescentes.

* $\quad$ Doutorando em Economia do Desenvolvimento pela FEA-USP. Mestre em Economia Política pela PUC-SP. Professor da Fundação Escola de Comércio Álvares Penteado (Fecap). E-mail: carvalho_andre@hotmail.com

*** Professor da Universidade Federal do Pampa. O autor agradece à Capes e ao CNPq pelo apoio financeiro durante seu período de doutoramento na Unicamp, quando o presente artigo foi elaborado. E-mail: eduardoangeli@unipampa.edu.br
} 


\section{Introdução}

A questão da incerteza enfrentada pelos agentes econômicos tem sido objeto de extenso debate dentro de e entre as diversas escolas de pensamento econômico. Como veremos, dois dos mais influentes economistas do século XX, J. A. Schumpeter e J. M. Keynes, são usualmente tidos como teóricos da dinâmica capitalista envolvendo argumentos em que a racionalidade detida pelos indivíduos possui um caráter mais restrito do que aquele existente na teoria convencional do equilíbrio geral, estando os agentes, assim, sujeitos a um tipo mais forte de incerteza.

Este trabalho procura compreender se a obra de outro dos principais economistas do século XX, o austríaco F. A. Hayek (1899-1992), pode ser vista também como se valendo do mesmo tipo de incerteza de que Keynes e Schumpeter tratam.

Lidaremos aqui com o primeiro momento da obra do austríaco ${ }^{1}$ : a análise hayekiana do ciclo econômico como resultado da divergência das expectativas dos agentes na tomada de decisão de gastos, divergência essa patrocinada pela falsificação da taxa de juros. Dado o papel central do crédito na sociedade capitalista moderna, Hayek (1933) percebe uma das manifestações claras do conhecimento limitado dos indivíduos, ao estabelecer as condições para que a moeda seja neutra. Nossa hipótese é que, de uma perspectiva hayekiana, o caráter não neutro da moeda pode ser um importante argumento na direção do reconhecimento de um tipo de incerteza mais forte que o adotado pela teoria econômica de cunho ortodoxo.

O papel da incerteza no quadro analítico hayekiano tornou-se sobejamente conhecido a partir de sua crítica ao conceito de equilíbrio da teoria neoclássica, com seu artigo de 1937, Economics and knowledge (HAYEK, 1948c). Nesse artigo, o autor apresenta as limitações contidas no tratamento neoclássico a dois elementos fundamentais da sociedade capitalista: o conhecimento e a concorrência. Ao destronar ambos os conceitos do pedestal da perfeição, o austríaco termina por salientar a característica subjetiva do conhecimento e sua inescapável

$1 \quad$ Ou seja, na etapa da obra hayekiana que autores como, entre outros, Caldwell (1988), Fleetwood (1995), Lucas (1977) e Soromenho (1994), identificam como a primeira fase da longa jornada de Hayek como cientista social, tratando, ainda, de temas mais circunscritos usualmente ao economista. A propósito, Lewis (2009) defende que a atenção que Hayek progressivamente passou a dar a questões envolvendo instituições emergiu de modo gradual com o amadurecimento de seu projeto de pesquisa. De fato, a obra de Hayek está permeada pela ideia de que a economia trata de questões envolvendo a coordenação (ou antes, sua falta ou incompletude) entre os diferentes participantes do processo de mercado, e que é por via do funcionamento deste processo que se promove um melhoramento na coordenação e na compatibilidade de planos e ações individuais. Dessa perspectiva, o institucionalismo hayekiano pode ser compreendido como a investigação acerca de quais os conjuntos institucionais que facilitam a descoberta, transmissão e interpretação do conhecimento existente na sociedade (conhecimento este caracterizado por ser difuso, tácito e subjetivo), e que conduzem, assim, a uma elevação do grau de coordenação entre os indivíduos que participam do processo de mercado. Ver também, a esse respeito, Garrison e Kirzner (1987). 
dispersão numa sociedade atomizada. Por esse caminho, Hayek busca enfatizar o caráter processual da economia, em contraponto à percepção de uma mudança discreta entre estados de equilíbrio. Para que a noção de processo se explicite, é necessário salientar a natureza histórica do tempo adotada pela teoria, em vez da percepção lógica do mesmo. Com efeito, a reversibilidade das ações possibilitada por uma análise fundada no tempo lógico deixa de fazer sentido.

Em Hayek, a articulação dos conceitos de conhecimento subjetivo, limitado e disperso e de irreversibilidade das ações no tempo histórico dá ensejo à possibilidade do erro. Por sua vez, o erro ocasiona a reformulação das expectativas dos agentes, conformando nova série de planos de ação que, na esfera do mercado, concorrerão entre si pela sua plena execução. Insere-se a separação temporal entre a decisão e a ação: admite-se a frustração das expectativas. Constitui-se, assim, a abordagem de processo, na qual a possibilidade de erro transmuta-se em oportunidade de ganhos. O conhecimento não é mais um conjunto de informações publicamente disponível; ele é, agora, uma capacidade de criação e descoberta. Logo, se há espaço para a criação e descoberta, existe, em alguma medida, conhecimento ainda não produzido. Assim, as escolhas devem levar em conta, além das restrições já conhecidas, resultados "imaginados" (BURCZAK, 1994, p. 45). Na presença desse fator "imaginação", todo um leito de incertezas aflui ao sistema teórico. O funcionamento da economia passa a depender das expectativas que os agentes têm frente às suas possibilidades futuras.

A percepção de que possuímos somente fragmentos do conhecimento global da sociedade - os quais são, em grande medida, contraditórios e incompatíveis entre si - origina-se nos estudos do austríaco em teoria econômica. A "transformação de Hayek" anunciada por Caldwell (1988) teve início quando de seus esforços em formular uma explicação para os ciclos econômicos, já na década de 1920 e início dos anos 1930. Os trabalhos que constituem esse esforço analítico foram escritos, portanto, antes e durante essa "transformação", caso se entenda que ela de fato tenha ocorrido. Nesses mesmos textos, já se apresentam termos e conceitos que seriam utilizados posteriormente na abordagem do problema do conhecimento, a saber, compatibilidade dos planos dos agentes, problema de coordenação das ações, dentre outros (SOROMENHO, 1994). Cumpre, portanto, analisar como surge o problema do conhecimento na teoria hayekiana dos ciclos.

Por isso, o objetivo deste artigo é buscar avaliar a hipótese de que a contribuição de Hayek ao estudo do ciclo econômico e da teoria da moeda, realizada sobretudo ao longo das décadas de 1920 e 1930, trazia consigo um tipo de incerteza em que, contemporaneamente a ele, Keynes e Schumpeter também lidavam. Na medida em que os três autores são seminais em ao menos três escolas de pensamento econômico atuais, tal esforço reconhece a importância dada à construção de pontes que possam facilitar a comunicação e mútua contribuição 
entre economistas de diferentes vertentes fora da ortodoxia neoclássica, como os austríacos, os neo-schumpeterianos e os pós-keynesianos. ${ }^{2}$

Assim, após esta introdução, a segunda seção expõe brevemente o que se entende por incerteza fundamental, conforme sistematizado por Dequech em alguns de seus trabalhos. Em seguida, a terceira seção trata da teoria hayekiana do ciclo econômico, articulando conceitos centrais a Hayek tais como moeda, conhecimento e coordenação. A quarta seção explicita que o mecanismo de mercado em Hayek pode, a partir de perturbações monetárias, falhar como coordenador entre os agentes, abrindo espaço para a incerteza fundamental. Por fim, a conclusão sumariza o argumento e aponta que Hayek continuou a transparecer a aceitação da incerteza fundamental em trabalhos posteriores.

\section{Variedades de Incerteza}

A discussão do conceito de incerteza em Hayek consistirá numa aplicação à sua obra da classificação de variedades de incerteza desenvolvida por Dequech (1997, 2000, 2004, 2006), bem como dos refinamentos, por esse autor, de diversos conceitos de incerteza. Em síntese, tal classificação estabelece o seguinte:

a) incerteza substantiva versus incerteza procedimental: ${ }^{3}$

a incerteza procedimental surge em função da limitação computacional e cognitiva dos agentes, buscando certos objetivos a partir das informações disponíveis, em lidar plenamente com a realidade complexa que os rodeia. Ou seja, a capacidade mental e/ou computacional dos indivíduos não é totalmente apta a captar, interpretar e analisar corretamente todas as facetas e dados do mundo. Isso envolve tanto a impossibilidade de coletar todos os dados quanto a de processá-los, inclusive através de computadores (que também são limitados);

a incerteza substantiva se refere à ausência de informações completas que seriam necessárias à correta tomada de decisão dos indivíduos. Ela se desdobra em diversos tipos de incerteza, que serão listadas abaixo. Dependendo de como são tratadas, incerteza substantiva e incerteza procedimental não são mutuamente exclusivas.

2 Koppl (2006) argumenta em favor de um esforço dos adeptos do paradigma austríaco rumo a uma maior integração com escolas de pensamento (inclusive nominalmente a pós-keynesiana) que ele chama de "nova ortodoxia emergente", marcada por características como, por exemplo, a aceitação de indivíduos possuidores de racionalidade limitada.

3 Os termos incerteza procedimental e incerteza substantiva são análogos à racionalidade procedimental e à racionalidade substantiva de Simon (DEQUECH, 2006). 
b) incerteza fraca versus incerteza forte é distinção entre tipos de incerteza substantiva:

com incerteza substantiva fraca os indivíduos não são criativos, possuem capacidade cognitiva e computacional perfeita (em oposição à incerteza procedimental) e suas ações não mudam a distribuição de probabilidade para cada estado de mundo futuro possível. Assim, não existe mudança estrutural envolvendo, por exemplo, mudança tecnológica. As pessoas não sabem como será o futuro, mas conhecem corretamente as probabilidades associadas a cada estado de mundo possível, havendo uma distribuição cuja soma é 1 . Dequech (1997) propõe uma divisão entre dois tipos de incerteza fraca encontrados, em geral, na literatura de inspiração neoclássica: em primeiro lugar, o risco knightiano apresenta probabilidade objetiva conhecida a priori (como num jogo de dados), teoricamente pré-estabelecida, ou probabilidade estatística (como na teoria da frequência), baseada em dados passados, determinada de forma empírica; em segundo lugar, a incerteza de Savage é o tipo de incerteza associado à teoria padrão da utilidade esperada subjetiva. Este tipo de incerteza parece ser mais comumente tratado nos manuais contemporâneos de microeconomia neoclássica, especialmente os de pós-graduação. Alguns autores adotam uma espécie de "subjetivismo radical", rejeitando a possibilidade de haver uma probabilidade objetiva, enquanto outros aceitam a existência de probabilidade objetiva, mesmo que não seja conhecida;

com incerteza substantiva forte os indivíduos não possuem fundamento para relacionar uma probabilidade a cada estado de mundo possivel futuro, e a distribuição de probabilidade sobre os eventos futuros é instável e tem soma menor do que 1. Nas palavras de Dequech, a incerteza forte é caracterizada "[...] by the absence of unique, additive and fully reliable probability distributions" (DEQUECH, 2006, p. 112). A incerteza knightiana talvez possa ser um exemplo de incerteza substantiva forte. ${ }^{4}$ Esse tipo de incerteza substantiva faz mais sentido ao ser desdobrado em ambiguidade e incerteza fundamental.

c) ambiguidade versus incerteza fundamental é distinção entre dois tipos de incerteza substantiva forte:

com ambiguidade a incerteza recai sobre a própria distribuição de probabilidade ${ }^{5}$. É possivivel haver distribuição de probabilidade sobre um determinado evento futuro; contudo o indivíduo não tem confiança nela, não há bases completas para que ela seja tomada como

4 Ligada à situação de probabilidade que Knight ([1921]1957, p. 225) chama de "estimativa". Dequech (2006) discute a utilização da incerteza knightiana como incerteza substantiva forte na literatura econômica.

5 Segundo Camerer e Weber (apud DEQUECH, 2006, p. 112), o conceito de ambiguidade trata de "[...] uncertainty about probability, created by missing information that is relevant and could be known". 
verdadeira. Nesse mundo, a lista de estados futuros é pré-determinada; o futuro (ou a lista de futuros possíveis), por assim dizer, já está criado. O problema com que a pessoa se defronta não é apenas desconhecer o que sucederá, mas é não saber as probabilidades associadas a cada ambiente possível. Essa incerteza quanto ao futuro chamada ambiguidade, então, surge em decorrência da falta de informação que existe e poderia ser conhecida, pois o futuro já está "definido", apesar de não se fazer sabido pelos indivíduos. A ideia de incerteza enquanto ambiguidade apresenta a deficiência de não ser capaz de lidar satisfatoriamente com a mudança estrutural do ambiente, com criatividade dos agentes ou com consequências não intencionais da ação humana, fatos por suas próprias naturezas incapazes de serem conhecidos antes de suas concretizações. ${ }^{6} \mathrm{O}$ exemplo principal de ambiguidade na literatura econômica é o chamado paradoxo de Ellsberg. ${ }^{7}$ Dequech (2000, p. 49) destaca que sob ambiguidade num ambiente dinâmico é possível que a quantidade de informação disponível aumente com a passagem do tempo. Assim, os agentes podem decidir esperar nova informação que mude suas distribuições de probabilidade e os façam ter mais confiança em um sub-conjunto delas (até que potencialmente a ambiguidade desapareça);

a característica principal da incerteza fundamental é que o futuro é "characterized by the possibility of creativity and non-predetermined structural change. The list of possible events is not predetermined or knowable ex-ante" (DEQUECH 2006, p. 112) e por isso ele "[...] cannot be anticipated by a fully reliable probabilistic estimate because the future is yet to be created." (DEQUECH, 2000, p. 48); a partir disso, não se pode ter uma distribuição de probabilidade confiável, verdadeira. A questão vai além da falta de informação: o problema é a sua inexistência. Com ambiguidade, a informação existia, apesar de não ser conhecida; já com incerteza fundamental, a informação não existe porque o futuro é aberto, impossível de ser plenamente conhecido e até concebido. Já que nem todos os cenários futuros podem ser imaginados, não se pode associar a cada um deles certa probabilidade. ${ }^{8}$

6 "A serious limitation of the notion of ambiguity is that it does not allow one to properly deal with creativity or with structural change in the decision-making environment, particularly a change due either creativity itself or to the unintended consequences of people's actions" (DEQUECH, 2000, p. 46).

$7 \quad$ O "paradoxo de Ellsberg" (ELLSBERG, 1961) parte do famoso jogo das cores das bolas dentro das urnas. As cores já estão definidas antes da pessoa decidir apostar ou não, e essa informação poderia ser conhecida, mas não é. Com base nas informações fornecidas, o potencial apostador cria em sua mente um conjunto de probabilidades possíveis e, a partir disso, toma sua decisão. A decisão dentre os estados de mundo que deverá prevalecer, a partir dessas probabilidades possíveis, é tomada com base em uma informação incerta, a partir da experiência, da sensibilidade, da indução do potencial apostador.

"As we cannot imagine it in the present, we cannot attribute to it any probability" (DEQUECH, 2000, p. 48). 
A noção de incerteza fundamental supre a deficiência do conceito de ambiguidade acima exposta, qual seja, a possibilidade de criatividade dos agentes e de mudança estrutural do ambiente. Não à toa, o conceito de incerteza fundamental é especialmente caro aos círculos pós-keynesianos e neo-schumpeterianos. Ele se encaixa no mundo onde as ações humanas alteram estados futuros, sendo que essas ações (e seus resultados não necessariamente intencionais) não podem ser antecipadas, como no caso do empresário schumpeteriano exposto acima. Nas palavras de Dequech (1999, p. 416), “[...] [i]n an environment where there is fundamental uncertainty, future actions can be created by today's decisions", e, assim, o futuro é sempre mutável, continuamente (re)construído.

A incerteza fundamental pode diminuir, mas não desaparecer, pela própria natureza das economias capitalistas. Ainda que cultura, instituições e regras tenham papel na redução da incerteza fundamental ao serem "ilhas de segurança num oceano de incerteza", o processo de concorrência intercapitalista e de busca incessante pelo lucro impulsiona as pessoas a inovarem e a procurarem novas formas de comportamento e produção.

Não por coincidência Dequech (2000) parece considerar a introdução de inovações na análise de Schumpeter (1996) da dinâmica capitalista como o exemplo par excellence de incerteza fundamental existente na literatura. A abordagem schumpeteriana se abre à possibilidade de agentes criativos e de mudança estrutural do ambiente econômico. Esta ocorre em virtude da ação do empresário inovador, caracterizando-se pela introdução de novos produtos e novas tecnologias e pela abertura de novos mercados. A ação do agente encarregado pela inovação não se dá após o cálculo matemático de ganhos ou perdas através do uso de todas as informações pertinentes ao seu campo, mas, sim, por um impulso interno à ação que marca sua inserção numa plataforma econômica competitiva, a qual constitui uma fonte de permanente pressão. Assim, podemos dizer que a participação do empresário schumpeteriano no processo de desenvolvimento econômico tanto acontece em meio a um ambiente de incerteza fundamental, quanto é a própria fonte dessa incerteza.

O conceito de incerteza fundamental é semelhante ao de não ergodicidade tratado por Paul Davidson e pela escola pós-keynesiana. Davidson chama de ambiente não ergódico aquele em que há incerteza ontológica advinda da possibilidade de mudança estrutural, vale dizer, aquele em que a incerteza está associada às características do ambiente e de sua possibilidade de mudança qualitativa, ao invés de mera limitação cognitiva dos agentes diante da complexidade, o que caracterizaria a incerteza chamada epistemológica, ou seja, relacionada ao conhecimento possuído pelo indivíduo.

A lembrança de Davidson se deve ao fato de Keynes ser, ao lado de Schumpeter, um autor comumente associado ao conceito de incerteza do tipo funda- 
mental. Contudo, essa talvez seja uma questão mais complexa do que a relativa a Schumpeter. Em seus primeiros escritos, notadamente em seu Tratado sobre Probabilidade (TP), Keynes (1921) parece fazer menção especialmente a ambiguidade. ${ }^{9}$ Explicamos: no TP, Keynes parte do princípio de que as proposições inicias de que os agentes se valem para principiar a formulação de hipóteses a respeito do futuro são conhecimento direto, no sentido de serem fruto da observação, e correto. A partir delas se pode chegar dedutivamente às conclusões sobre como será o futuro, estas sim na forma de probabilidades, que por se basearem logicamente em conhecimento verdadeiro, são também verdadeiras. O peso do argumento de que Keynes fala no TP é o grau de completude das premissas iniciais; isso porque, ao mesmo tempo em que o inglês assume que elas são corretas, não afirma que são completas. É essa possível não disponibilidade de conhecimento relevante que faz surgir a incerteza, no sentido de ambiguidade. Segundo Carvalho (1988), o passo decisivo dado por Keynes no sentido de adotar a incerteza típica de seus escritos maduros, a de tipo fundamental, foi o relaxamento da condição de verdadeiras atribuída às premissas inicias. Em outras palavras, Keynes, a partir especialmente de sua Teoria Geral (KEYNES, 1996), passou a lidar com a precariedade com que tais premissas são erigidas, dando especial valor, então, às convenções que servem, de certa forma, como guias às decisões de alocação de riqueza dos indivíduos.

\section{Moeda, Conhecimento e Incerteza na Teoria dos Ciclos de Hayek}

A teoria dos ciclos de Hayek é uma obra extensa ${ }^{10}$ que abrange diversos artigos e livros, os quais refletem uma trajetória de amadurecimento da análise do autor, que, em boa medida, deve-se às críticas de seus pares ${ }^{11}$. Hayek (1977) confirmou que nunca buscou compreender como suas ideias se encaixavam num painel analítico único. Com efeito, conceitos importantes tratados em um livro ou artigo são tomados como dados em trabalhos subsequentes. Daí a importância de se avaliar o pensamento de um autor contemplando o conjunto de sua obra. No

9 A interpretação de que não há uma continuidade entre os escritos de cunho mais filosófico de Keynes e sua obra posterior, mais focada em assuntos econômicos, em particular no que tange à questão da incerteza, não é nem de longe consenso entre os estudiosos da obra do britânico. A interpretação que ora seguimos está fundada especialmente em Carvalho (1988). Segundo Dequech, "[s]ituations of ambiguity appear in his [Keynes's] A Treatise on Probability [...] It is particularly in his later economic writings that Keynes refers to situations of fundamental uncertainty" (DEQUECH, 2000, p. 50). Daí Dequech (2000) alertar sobre a imprecisão da expressão "incerteza keynesiana": ao lançar mão dela, é preciso que se esclareça se é feita referência à incerteza fundamental ou à ambiguidade.

10 A teoria hayekiana dos ciclos econômicos está distribuída em diversos artigos e livros, os quais podem ser encontrados em Hayek (1984; 1966; 1950; 1935).

11 Extrapolaria os limites do presente artigo uma extensa avaliação da evolução da teoria dos ciclos de Hayek e sua relação com a teoria austríaca do capital. Sobre isso, veja-se, por exemplo, a coletânea que Caldwell (1995) organizou sobre o debate de Hayek com Keynes e Sraffa. 
que se refere à incerteza, é possível interpretar seu surgimento na teoria hayekiana dos ciclos de, pelo menos, duas maneiras correlacionadas. Uma delas já foi discutida por Soromenho (1998), entendida como efeito de uma falta de coordenação das ações dos empresários em diferentes estágios da estrutura produtiva no âmbito da teoria austríaca do capital, assim como em Hayek ([1941] 1975). Uma forma alternativa é a análise do desequilíbrio que emana do funcionamento da organização monetária do sistema econômico. Como se sabe, a questão monetária ocupa papel central na teoria austríaca dos ciclos econômicos, contida, por exemplo, em Mises (1978), Hayek (1966) e, mais recentemente, em Horwitz (2000) e Garrison (2001; 2004). Essa última é a opção adotada no presente artigo.

Para sugerir a existência de incerteza fundamental é necessário demonstrar como Hayek enxergava o papel das expectativas nos ciclos econômicos. Em seu livro Monetary Equilibrium, Myrdal (1965) inicia fazendo uma crítica das principais teorias monetárias da época, a saber, as de Keynes e Hayek, dizendo que "A criticism of Keynes and Hayek would have to begin by pointing out the fact that in their theoretical systems there is no place for the uncertainty factor and for anticipations." (MYRDAL, 1965, p. 32).

Um pouco mais à frente, após considerar as limitações do Treatise on Money de Keynes, ele se volta para a teoria de Hayek, acentuando que, nela, a abordagem se dá no estado estacionário ou quase estacionário. Nesse estado, prevalecem o conhecimento perfeito e a concorrência perfeita. ${ }^{12}$ Ao definir a abordagem de Hayek como sendo de estado estacionário, o economista sueco atribui ao modelo do austríaco, mesmo que implicitamente, a contradição que ele percebe na utilização do conceito de concorrência perfeita para a explicação do ciclo. (MYRDAL, 1965, p. 33). Ademais, Myrdal alega que as suposições fortemente abstratas que Hayek faz impedem o tratamento do risco e da incerteza nesse quadro analítico, desconsiderando o papel das antecipações. ${ }^{13}$ Ele não detalha, entretanto, as suposições específicas a que se

12 Essa constitui uma das tensões internas ao pensamento de Hayek. A teoria austríaca do capital é formada com base no paradigma do equilíbrio, de forma que a análise parte do pressuposto de que os setores que formam a estrutura produtiva da economia encontram-se perfeitamente integrados entre si. Esse é um obstáculo relevante quando se quer explicar o fenômeno do ciclo que era tido como um desequilíbrio da economia. Como ressalta Soromenho (1998, p. 515): "[...] ao centrar sua atenção no estado estacionário, as apresentações formais da teoria austríaca supunham já existente o equilíbrio entre os diversos componentes do equipamento produtivo da sociedade; assumiam, portanto, resolvido o problema de coordenação das ações dos diversos empresários produtores dos bens de diferentes ordens".

13 "Hayek's work, as compared with that of Keynes, have the merit of a more intensive analysis of the roundabout process of production and consequently of the questions of profitability. But Hayek's analysis is stationary or quasi-stationary only, and I cannot see how he would be able to work the risk and uncertainty factor into his system, which is bound by very abstract assumptions, which simply cannot be removed [...] Hayek directs his thorough analysis - in accordance with the Austrian tradition - towards an abstract case where among other things anticipations are excluded by assumptions which are fundamental to the whole analysis" (MYRDAL, 1965, p. 33). 
refere, dizendo somente que ambos Hayek e Keynes têm intuições mais potentes do que suas teorias lhes permitiam dizer.

Sem o aval de Myrdal seria, portanto, difícil especular sobre as suposições que, em sua visão, impediriam a visualização mais nítida do papel desempenhado pelas expectativas na teoria hayekiana dos ciclos. Todavia, Hicks (1967, p. 206) sugere uma pista, ao perceber, no trabalho Prices and Production de Hayek (1935), a ausência das expectativas de preços, uma vez que "[...] ainda não havia chegado a hora" de as mesmas serem incorporadas à teoria. Então, ele supõe que:

There must, however, have been some implicit assumption about expectations. We shall hardly go wrong if we take it to be the simplest possible assumption: the 'static' assumptions. The same prices as rule today (whatever they are) are expected to continue to rule in the future. (HICKS, 1967, p. 206).

A intuição de Hicks é confirmada por um texto pouco conhecido de Hayek, o qual contém a transcrição de uma palestra apresentada em Copenhagen (HAYEK, 1950) no ano de 1933. Essa palestra respondia à provocação de Myrdal. Nessa resposta, Hayek formulou uma versão da teoria dos ciclos baseada nas expectativas dos agentes, tornando explícito aquilo que, como disse Hicks, havia permanecido implícito no texto de 1931. Essa palestra faz parte de um conjunto de artigos em que Hayek (1950) busca reexpor, ajustar e repensar sua teoria monetária dos ciclos em virtude das diversas revisões críticas que recebeu. Contudo, antes de analisarmos mais cuidadosamente a palestra de Copenhagen, é importante introduzirmos um conceito crucial para a compreensão da teoria hayekiana dos ciclos, a saber, o conceito de poupança forçada.

\subsection{Conceito de Poupança Forçada em Hayek}

A teoria dos ciclos de Hayek salientava o impacto de um aumento na quantidade de moeda sobre a produção de capital, tanto diretamente quanto mediado pelo mecanismo da taxa de juros. O mecanismo que associava moeda e produção de capital recebeu o nome de poupança forçada. (HAYEK, 1935). Hayek buscou se aprofundar no conceito de poupança forçada de forma a investigar os fatores que deflagravam os ciclos econômicos, integrando os lados real e monetário da economia. O autor organizou um estudo (HAYEK, 1950) sobre a evolução do conceito ao longo da história do pensamento econômico, identificando Jeremy Bentham como o pioneiro na percepção do fenômeno, tendo sido utilizado por uma constelação de pensadores ilustres como Malthus, Ricardo, J.S. Mill, Walras, Wicksell, Keynes, dentre outros. ${ }^{14}$

14 Bentham já tratava, em 1804, da "frugalidade forçada", a qual se definia por um acréscimo na massa de riqueza futura, garantida pela destinação dos fundos arrecadados pelo governo, por 
Para Hayek, o termo poupança forçada era uma "expressão infeliz" para definir o fenômeno em questão. (HAYEK, 1966). O autor associava a poupança forçada a um excesso de investimento resultante da expansão do crédito. Este por sua vez gerava uma realocação da riqueza social sem que os indivíduos se dessem conta dela, senão somente quando seus efeitos se fizessem sentir no aumento de preços. Nesse sentido, a poupança forçada:

[...] causes a part of the social dividend to be distributed to individuals who have not acquired legitimate claim to it through previous services, nor taken them over from others legitimately entitled to them. It is thus taken away from this part of the community against its will (HAYEK, 1966, p. 220).

Uma formalização simples do fenômeno pode facilitar a compreensão. Desconsiderando-se, nesse estágio da apresentação, os efeitos em termos da alocação dos recursos disponíveis, suponha-se uma economia em pleno emprego ${ }^{15}$ em que a

meio de impostos - ou pela criação de papel-moeda -, à produção de bens de capital. (HAYEK, 1966, p. 18). A primeira análise mais detalhada do problema foi, contudo, a de Thomas Malthus, em 1811. O autor britânico já enfatizava a necessidade de se verificar a influência de uma distribuição desigual dos meios circulantes sobre a acumulação de capital, destinada a facilitar a produção futura. Isso seria conseguido pela mudança na razão entre o capital e sua receita, de forma a concentrar o produto da economia nas mãos das classes produtivas. Adicionalmente, Hayek cita autores como Thomas Joplin e J. S. Mill, tendo esse último mencionado o problema sob o termo "acumulação forçada", sem conceder maior importância ao fenômeno. O economista austríaco afirma que por muitos anos esse problema foi desconsiderado pela teoria, tendo sido retomado somente em 1879, por Leon Walras. Foi por meio dos estudos do economista francês que a doutrina da poupança forçada chegou ao conhecimento de Knut Wicksell. A análise crítica sobre a teoria wickselliana ensejou a consolidação da poupança forçada como elemento central da análise hayekiana dos ciclos. (HAYEK, 1966, p. 26). Depois de Wicksell, outros autores chegaram a identificar o fenômeno. Dentre eles, destacam-se, no continente europeu, Ludwig von Mises (1912) e Joseph Alois Schumpeter (1996). Em Cambridge, na Inglaterra, reconhecem-se os trabalhos de D. H. Robertson e sua Imposed Lacking, de Arthur Pigou e sua "Forced Levies" e, por fim, John Maynard Keynes, "[...] who discusses the same problem in his Treatise on Money, [but] rejects this terminology and prefers to speak simply of investment being in excess of saving" (HAYEK, 1950, p. 196-197). Nesse ponto, Hayek admite que Keynes foi muito feliz em omitir o termo em seu Treatise on money. Ao comentar a rejeição do autor britânico à terminologia, Hayek (1950, p. 196-197) diz: "[...] and there is much to be said in favor of this".

15 É condição necessária do modelo que a economia esteja em estado de pleno emprego (HAYEK, 1935, p. 86). Trata-se de uma suposição feita por diversos teóricos da época em que Hayek escreve, como Wicksell, Mises e Myrdal. Dennis Robertson propunha uma visão diferente, utilizando o conceito de poupança forçada quando a economia estava abaixo do pleno emprego. Robertson entendia, contrariamente a Mises e Hayek, que o mercado não possibilita a alocação adequada da poupança nos setores adequados. Os austríacos tomavam essa possibilidade como uma condição necessária. Como a poupança voluntária não é perfeitamente distribuída, os bancos teriam um papel relevante em ofertar a quantidade de moeda necessária para a expansão da capacidade produtiva. A poupança forçada seria, assim, um fenômeno benigno. Laidler qualifica essa suposição, dizendo que: "Robertson's particular stress on the provision of short-term capital by way of forced saving reflects the practices of the British and American commercial banking systems. Any careful comparison of Austrian and Robertsonian treatments of forced saving needs to pay attention to the different assumptions about the nature of banking institutions that were usually left implicit in their analysis." (LAIDLER, 2006, p. 17). 
renda real agregada seja uma função dos salários $(w)$ e dos lucros $(\pi)$ recebidos, dada por $y=f(w, \pi)$ ou $y=w+\pi$. Adicionalmente, admite-se que a condição de equilíbrio da renda de curto prazo tenha a seguinte forma:

$$
\bar{y}=a . w+b . \pi
$$

onde $a$ e b são parâmetros que denotam, respectivamente, a proporção da riqueza social, dada em termos monetários, comandada pelos salários e pelos lucros, de maneira que $a+b=1$. Dessa forma, mantidos os investimentos constantes, a ampliação do volume de crédito gera um aumento no poder de compra geral da economia. Entretanto, esse acréscimo tem um ponto de injeção específico representado pelo sistema bancário. No modelo de Hayek, o crédito somente pode ser destinado aos empresários.

Assim, de acordo com a equação acima, como a riqueza social real y permaneceu inalterada, o acréscimo de poder de compra alterou as proporções do produto social comandadas pelas duas classes de indivíduos. Definindo-se o acréscimo de poder de compra pelo parâmetro $c$, pode-se reescrever a equação da renda da seguinte forma:

$$
\begin{gathered}
\bar{y}=a \cdot w+(b+c) \cdot \pi, \text { ou } \\
\bar{y}=a^{\prime} \cdot w+b^{\prime} \cdot \pi
\end{gathered}
$$

onde $a^{\prime}<a$ e $b^{\prime}>b$, uma vez que $a+(b+c)=1$. Fica demonstrado, portanto, o efeito distributivo da expansão do crédito, que Hayek definiu acima como uma transferência ilegítima - isto é, sem o consentimento da comunidade - de recursos para alguns indivíduos. A peculiaridade da teoria hayekiana reside na destinação desses recursos para as mãos dos empresários, gerando uma alteração na estrutura produtiva da economia que, por se fundar numa poupança fictícia - fundada sobre a acomodação do excesso de demanda por fundos por meio da elasticidade da oferta de crédito bancário -, gera uma falsificação da taxa de juros. Essa falsificação corrompe a coesão entre as preferências intertemporais dos agentes da economia, dirigindo os empresários a inverter um volume de investimentos maior do que a sociedade está disposta a financiar. Os desdobramentos desse fenômeno sobre a alocação dos fatores produtivos serão explicitados ao longo do estudo da palestra de 1933.

\subsection{Expectativas e Conhecimento na Teoria dos Ciclos de Hayek}

A palestra de Copenhagen, proferida em dezembro de 1933, guarda elementos importantes para a compreensão do desenvolvimento intelectual de 
Hayek. Transcrita no quarto capítulo do livro Profits, Interest and Investment (HAYEK, 1950) e intitulada Price Expectations, Monetary Disturbances and Malinvestments (HAYEK, [1933] 1950, p. 135-156), seu propósito é discutir o papel das expectativas na teoria econômica, principalmente na formulação de explicações dinâmicas sobre os fenômenos econômicos. Nela se percebe um ponto crítico da trajetória de Hayek. É nesse momento exato que o autor deixa explícita a sua insatisfação com o conceito de equilíbrio da "teoria tradicional" neoclássica e com a premissa de previsão perfeita (CALDWELL, 2005) ${ }^{16}$ É suficiente, dado o escopo desse artigo, entender como Hayek expõe a existência da incerteza (em oposição à previsão perfeita) e, por conseguinte, da relevância das expectativas.

It has become clear that, instead of completely disregarding the time element, we must make very definite assumptions about the attitude of persons towards the future. The assumptions of this kind which are implied in the concept of equilibrium are essentially that everybody foresees the future correctly and that this foresight includes not only changes in the objective data but also the behaviour of all the other people with whom he expects to perform economic transactions. (HAYEK, 1950, p. 139-140).

A necessidade de a teoria econômica considerar os aspectos temporais constitui uma antiga reivindicação da escola austríaca que remete a seu fundador, Carl Menger (BORCH, 1973). ${ }^{17}$ Num famoso artigo de sua juventude, Hayek (1984) inicia sua apresentação com a frase: "[...] toda a atividade econômica se dá no tempo". O aspecto temporal impõe aos indivíduos a irreversibilidade de suas decisões e ações. Mas Hayek não se satisfaz com a mera postulação de tal corolário. É preciso demonstrar, a partir de sua teoria, como surge a incerteza. Em outros termos, é preciso anular a validade do conceito de previsão perfeita.

No capítulo 2 de Monetary Theory and the Trade Cycle (1966), Hayek analisa a validade das teorias não monetárias dos ciclos, fazendo uma crítica das teorias que baseavam suas explicações em fundamentos psicológicos do mundo dos negócios. Na palestra de 1933, Hayek retoma a ideia de tais teorias e declara novamente sua objeção - sem, contudo, endereçá-la nominalmente - às mesmas.

16 A consideração detalhada dos fatores que permitem estabelecer essa ligação pode ser encontrada em Carvalho (2007).

17 Segundo Hayek, "The main difficulty of the traditional approach is its complete abstraction from time. A concept of equilibrium which essentially was applicable only to an economic system conceived as timeless could not be of great value". (HAYEK, 1950, p. 139). Todavia, Borch (1973, p. 62) aponta que a ideia de uma "[...] simetria entre tempo e incerteza" persiste na escola austríaca, apesar de nunca ter sido claramente demonstrado como essa simetria poderia ser explorada pela análise econômica. 
Every explanation of economic crises must include the assumption that entrepreneurs have committed errors. But the mere fact that entrepreneurs do make errors can hardly be regarded as a sufficient explanation of crises. Erroneous dispositions which lead to losses all round will appear probable only if we can show why entrepreneurs should all simultaneously make mistakes in the same direction (HAYEK, 1950, p. 141).

Entretanto, atribuir tais erros a um tipo de "infecção psicológica" não é suficiente. É mais convincente alegar que os empresários:

[...] may all be equally misled by following guides or symptoms which as a rule prove reliable. Or, speaking more concretely, it may be that the prices existing when they made their decisions and on which they had to base their views about the future have created expectations which must necessarily be disappointed. In this case we might have to distinguish between what we may call justified errors, caused by the price system, and sheer errors about the course of external events. (HAYEK, 1950, p. 141).

Hayek escolhe o problema do investimento, uma vez que as decisões dos empresários dependem exclusivamente de sua avaliação acerca do curso futuro dos eventos. Esse é um caso importante em que as decisões dos mesmos são afetadas pela situação geral do mercado financeiro e não pela posição relativa das indústrias. Em outros termos, é a relação entre decisões e sistema monetário que está em foco, e não aspectos referentes à concorrência intra e inter mercados. Mudanças no mercado financeiro têm efeitos abrangentes por toda a economia. Mais que isso, tais efeitos perduram no tempo, de forma que o sucesso de um investimento depende não só da situação do mercado de capitais no presente, mas também dos eventos futuros.

A execução de um projeto de investimento se dá ao longo do tempo e, por isso, sua viabilidade está condicionada à disponibilidade de recursos em datas futuras para sua conclusão. Hayek faz sua primeira formulação acerca das expectativas dos empresários, dizendo que,

In general it is probably true to say that most investments are made in the expectation that the supply of capital will for some time continue at the present level. Or, in other words, entrepreneurs regard the present supply of capital and the present rate of interest as a symptom that approximately the same situation will continue to exist for some time. (HAYEK, 1950, p. 142).

Além disso, o sucesso de um investimento está condicionado à conclusão de investimentos em setores que produzem bens complementares. O que Hayek 
tem em mente aqui é um aprofundamento da divisão das atividades produtivas. Uma firma encurta a parte do processo pela qual ela é responsável, sendo a parte abandonada assumida por outro grupo de empresários. Assim, é imperativo que a oferta de capital se mantenha não só para um empresário individual, mas para todos aqueles que participam desse específico processo produtivo, de forma que o novo aparato de produção possa ser concluído, com suas etapas devidamente sincronizadas.

O que causaria, então, variações inesperadas na oferta de capital, levando à frustração das expectativas dos empresários? Hayek descarta a possibilidade de oscilações bruscas na oferta de poupança voluntária, alegando que a "experiência" mostra que tais flutuações ocorrem somente como resultado das crises e não de forças internas do sistema. Hayek busca isolar, portanto, o fator efetivamente causador das crises: as perturbações monetárias causadas pela organização do sistema de crédito. $O$ crédito permite que a oferta de capital financeiro supere o montante de poupança disponível; o efeito disso é a variação na quantidade e na velocidade de circulação que torna a oferta de capital para investimentos independente da oferta de poupança voluntária.

This means, however, that entrepreneurs will often base their decisions about their investment plans on a symptom which in no way indicates even the current willingness of the consumers to save, and therefore provides no guide whatever for a forecast of how they will distribute their income in the future between consuming and saving. (HAYEK, 1950, p. 144).

Os desdobramentos que se seguirão advirão de uma incompatibilidade entre: (1) a distribuição da renda corrente dos consumidores entre consumo presente e consumo futuro e (2) a divisão dos recursos dos empresários entre a produção para o futuro próximo e a produção para um futuro mais distante.

No desequilíbrio, retratado como uma perturbação monetária ocorre uma falha de comunicação. Enquanto os empresários destinam recursos para a produção mais distante no futuro, os consumidores são incapacitados de expressar seus desejos claramente, uma vez que, ainda nesse primeiro momento, suas rendas não foram afetadas. Quando os créditos emitidos chegam ao mercado na forma de salários (tanto pelo aumento dos rendimentos dos trabalhadores disputados pelos empresários quanto pela absorção de trabalhadores previamente desempregados), os preços dos bens de consumo sofrem pressão. Os planos de consumo de vários indivíduos são frustrados pelo fenômeno da poupança forçada. Como a quantidade de bens disponíveis não se eleva automaticamente, a renda adicional dos consumidores só pode adquirir os bens existentes. A intensidade da elevação dos preços dos bens de consumo é condicionada, portanto, pela distribuição entre consumo e poupança dos agentes econômicos. A intensificação da produção de 
bens de consumo resultante do incremento da capacidade instalada da economia virá somente muito mais tarde. Mesmo assim, Hayek reconhece que a melhoria na disponibilidade de bens de consumo representará somente uma fração da renda adicional gerada pelo investimento. Em termos mais concisos, a renda cresce mais depressa do que a escala de produção. Tem-se, portanto, que o problema central reside na relação entre o aumento na renda dos consumidores e o incremento na produção de bens de consumo.

Hayek percebe a existência de uma incompatibilidade intertemporal entre os planos dos agentes, a qual toma a forma de um conflito pelos recursos da economia. Tal conflito não se manifesta senão muito tarde, quando a economia já se aproxima do final da fase próspera do ciclo. No que se refere à dimensão temporal da crise, o conflito nasce porque a maturação dos planos dos empresários é mais tardia quando comparada às perspectivas de consumo dos agentes. A manutenção desse desequilíbrio exige que o sistema bancário continue emitindo crédito, de forma a garantir a viabilidade de todos os projetos de investimento. Entretanto, a preferência pela liquidez dos bancos (TRAUTWEIN, 1994) impede a expansão contínua do crédito, engendrando inevitavelmente o fracasso de inúmeros projetos de investimento. (HAYEK, 1950).

Na palestra de 1933, em Copenhagen, Hayek estava preocupado em demonstrar a possibilidade de ocorrência de erros, mas de um tipo específico de erro. A crítica de Myrdal permitiu a Hayek enfatizar um ponto que havia recebido menor atenção em textos anteriores e que é crucial para a compreensão de sua teoria monetária: o modelo da concorrência.

\section{A Possibilidade de Falha do Mercado como Mecanismo Coordenador e a Incerteza Fundamental}

Hayek pressupõe que o sistema de preços, principalmente a taxa de juros, seja um parâmetro fiel das preferências intertemporais dos agentes. Nesse caso, é lícito admitir que, em seu Prices and Production, o austríaco adota uma teoria dos preços plenamente "funcional". O objetivo dessa abordagem é estabelecer as condições para a configuração de preços consistentes com um estado de equilíbrio, sem se ater ao processo de formação dos mesmos no mercado (BOEHM, 1992). Na ausência de perturbações monetárias, os preços comunicariam com fidelidade as informações relevantes para as decisões dos agentes. ${ }^{18}$

18 É válido acrescentar a exposição de Soromenho acerca do papel "economizador" de informação que Hayek atribui ao sistema de preços, o qual "atuava no sentido de compatibilizar as iniciativas empresariais. As ações dos empresários concorrentes refletem-se nos custos de cada empreendedor isoladamente considerado, induzindo-o a adotar a atitude correta. Não é necessário que $\mathrm{o}$ agente conheça as iniciativas dos concorrentes. $\mathrm{O}$ aumento dos seus custos leva-o a restringir a expansão de sua produção de tal modo que, quando se considera a totalidade das empresas 
O mercado, para Hayek, funciona como um ambiente complexo e coordenador em que os indivíduos dotados de conhecimento imperfeito são guiados por sinais abstratos. O sistema de preços atua como comunicador impessoal das informações relevantes (LOASBY, 1989), tornando compatíveis planos individuais outrora incompativeis (O)DRISCOLL, 1977). ${ }^{19}$ O problema que se levanta é que o sistema de preços pode falhar nessa sua função, transmitindo informações incorretas acerca das condições particulares de oferta no processo de ajustamento à demanda. Ou seja, o sistema monetário pode gerar uma perturbação que falsifica o principal parâmetro para a formulação dos planos de ação. O resultado dessa distorção do sistema de preços é a incompatibilidade intertemporal entre os planos dos consumidores e dos empresários. ${ }^{20}$

O que Hayek defende é exatamente a limitação da cognição humana, a ponto de o problema de Hayek ser o problema do conhecimento (BARBIERI, 2006), explicitado após seu artigo de 1937. O intelecto do ser humano não consegue dar conta de apreender e processar todas as informações que influenciam os preços, que funcionam, por isso, como uma espécie de "sintetizador" do conhecimento difuso entre os inúmeros participantes do processo de mercado.

Tendo-se essas considerações em vista, é possivel fazer uma leitura mais compreensiva da teoria hayekiana dos ciclos. Os agentes nesse modelo detém conhecimento limitado, daí a importância do sistema de preços. O que difere o sistema de trocas puras do sistema de trocas indiretas não é a escassez de informações: essa é uma característica central do mundo real. O que os difere entre si é que, no sistema mediado pela organização monetária, o sistema de preços pode não funcionar, isto é, ele é altamente vulnerável às variações na quantidade de moeda. Mesmo que o sistema econômico em seu lado real funcione adequadamente, o mercado bancário é um locus em que a orientação das ações não se dá pelo sistema de preços desse mercado, isto é, a taxa de juros. Para Hayek, os bancos não conseguem identificar quando suas reservas disponíveis para empréstimo deixaram de ser definidas pela poupança voluntária e passaram a ser co-determinadas pela variação da base monetária.

do setor, a oferta agregada do produto mostra-se compatível com a capacidade de absorção do mercado. O mercado funciona sem que os agentes que dele participam tenham a necessidade de conhecer todos os fatores que o afetam." (SOROMENHO, 1994, p. 163).

19 Não por acaso, o livro de O'Driscoll (1977) sobre Hayek se chama Economics as a coordination problem.

20 "Mises and Hayek both felt that the crucial problem that any theory of the trade cycle must illuminate and help us understand is the 'cluster of errors' that occurs during a bust. [...][T]he Mises-Hayek theory suggests that business error occurs because intervention in the loanable funds market (manipulation of the interest rate) produces 'false' signals which businessmen act upon. Since most loans, at that time, were lent to business concerns, the artificially lower rate signalled businessmen to borrow money and invest in production processs that otherwise would not have appeared profitable. The corresponding malinvestiments reveal themselves when markets adjust to convey the underlying preferences of consumers and producers" (BOETTKE, 1989, p. 187). 
Nessa situação, que Hayek define como sendo a circunstância comum, os parâmetros adotados pelos bancos para guiar suas decisões se deslocam para outros fatores, basicamente, grau de liquidez (ou de solvência) da firma bancária e sua interpretação a respeito da situação geral dos negócios. A leitura da economia depende, é claro, da posição relativa dos bancos no sistema econômico. Em outras palavras, se a firma bancária está preocupada com sua lucratividade e com sua solvência, é possível aferir que sua interpretação acerca do nível de atividade da economia está associada aos setores em que atuam seus clientes. Isso fica claro quando se relembra o exemplo dado por Hayek (1966), em seu Monetary Theory and the Trade Cycle, de um gerente de banco que percebe o aquecimento da atividade econômica pelo aumento da demanda de crédito por parte de clientes que atuam no mesmo setor da produção. É por meio dessas demandas localizadas que os bancos analisam a situação da economia, a qual, juntamente com a posição de caixa da firma bancária, forma o conjunto central de informações para tomada de decisões no mercado bancário.

Se for esperado que o ambiente se aqueça diminui a percepção do risco de cada empréstimo por parte dos bancos, sancionando-se a expansão do crédito (ARIDA, 1981). Da mesma forma, os sintomas da crise virão pelos mesmos meios. Como o crédito não é heterogêneo, mas uma massa homogênea, a ameaça de insolvência ocasionará a elevação da taxa de juros para todos os projetos indistintamente, inclusive para aqueles setores que gozam uma posição privilegiada em seus rendimentos e nas suas perspectivas futuras de negócios. Em virtude desse déficit informacional, os bancos se atrasam em elevar a taxa de juros, permitindo que a expansão do capital físico da economia exceda as possibilidades reais disponíveis, em termos de capital financeiro, para a sua manutenção.

Dessa forma, a origem do problema da informação reside na conjugação de dois fatores: a formação de precárias expectativas, por parte dos bancos, em relação ao curso futuro da economia, e a elasticidade da oferta de crédito. A articulação de ambos dá ensejo à profecia auto-realizável da ocorrência das crises: é como se os empresários fossem enganados de ambas as pontas de sua relação com o sistema econômico. De um lado, os bancos sinalizam uma taxa de juros para o financiamento dos projetos, que os empresários entendem será mantida até a conclusão dos mesmos. De outro, os consumidores sinalizam pelo montante de poupança voluntária, via taxa de juros, uma intenção de consumir num futuro remoto. Contudo, ambos se antecipam na correção de suas posições iniciais: os bancos encarecem os financiamentos e os consumidores decidem consumir mais no presente.

In such a situation there exists evidently a conflict between the intentions of the consumers and the intentions of entrepreneurs which earlier or later must mani- 
fest itself and frustrate the expectations of at least one of these groups. The situation is certainly not one of equilibrium [...]. (HAYEK, 1950, p. 145).

Dadas as expectativas, o impulso gerado pela elevação artificial da oferta de capital financeiro ocasiona erros, por parte dos empresários, que se dão na mesma direção: a expansão excessiva dos investimentos. Hayek fundamenta, de maneira adequada à sua abordagem monetária, a teoria dos ciclos baseada nos erros de previsão dos agentes econômicos. Em outras palavras, duas formas de frustrar a certeza dos agentes em relação ao futuro. Existem duas potenciais origens de incerteza que acometem os agentes. No caso dos empresários, há a incerteza em relação ao produto que será obtido por cada fator de produção e o preço pago pelos bens produzidos no mercado $(\mathrm{BORCH}, 1973)$. Além disso, há uma incerteza quanto a se esse fator estará disponível para aquisição (no caso dos setores que produzem bens complementares entre si não conseguirem se integrar sincronizada e quantitativamente, no que se refere à disponibilidade dos bens produzidos).

Pode-se acrescentar outra fonte de incerteza: aquela referente aos preços pagos pelo lado da demanda. Considerando-se que há uma relação de oferta e demanda entre os estágios produtivos, no caso de uma elevação inesperada dos preços de um insumo qualquer, alguns setores sofrerão redução em sua taxa de lucro. Mesmo na eventualidade de uma baixa drástica na remuneração dos fatores, oriunda da elevação exorbitante de um insumo produtivo, esse tipo de incerteza só é relevante na fase recessiva do ciclo, uma vez que na fase expansiva há oferta de crédito disponível a taxas de juros constantes, o que permite contornar facilmente esse obstáculo. ${ }^{21}$

No que diz respeito à demanda dos bens de consumo, o fenômeno se dá de outra maneira. Com base no conceito de poupança forçada, Hayek mostra que os consumidores têm sua renda transferida involuntariamente para os empresários. Nesse sentido, os salários e os rendimentos recebidos pelos consumidores sofrem uma perda em seu poder de compra.

Imagine-se, por exemplo, que um indivíduo recebeu uma quantia em dinheiro e decide gastá-la na compra de um bem qualquer. Entre o momento em que o indivíduo adquire uma quantia de dinheiro e o momento em que ele efetua a troca, as mudanças ocorridas no âmbito do mercado de fundos emprestáveis podem ter alterado significativamente os "dados" que o indivíduo levou em conta ao formular o seu plano de ação (isto é, a resolução de gastar aquele montante na compra de um bem). Assim, as premissas que embasaram sua decisão podem não

21 É claro que a superação desse empecilho é relativa. A contratação de mais crédito ampliará o montante da receita advinda da venda dos produtos destinado ao pagamento das dívidas bancárias. Entretanto, quando a firma se encontra num ambiente econômico aquecido, o otimismo das previsões impera e esse deixa de ser um problema, pelo menos no prazo imediato. 
mais corresponder à situação efetiva; em suma: o agente tem seu plano frustrado. A questão é: teria ele como saber dessas alterações?

Como se viu, a existência da moeda gera uma série de incertezas na economia. Nesse caso, a moeda não cumpriria o desempenho esperado pelos agentes da economia: facilitar as transações sem perturbar os preços. Em outras palavras, ela deixaria de ser neutra. Assim, uma das condições para a neutralidade da moeda seria que todos os contratos de longo prazo fossem baseados na correta antecipação dos movimentos futuros dos preços (HAYEK, 1935).

Por isso, perante as adversidades trazidas pela moeda, a pergunta que resta é como seria possível garantir que as previsões fossem efetivamente corretas, num ambiente em que o sistema de preços é recorrentemente distorcido pelas perturbações monetárias.

\subsection{Caráter da Incerteza na Economia Monetária de Hayek}

Se a fonte da incerteza é a ação dos agentes dotados de conhecimento imperfeito, podemos dizer que em Hayek, a incerteza possui um caráter tanto epistemológico quanto ontológico, ou seja, tanto a capacidade cognitiva dos agentes frente à realidade complexa é limitada, quanto a própria realidade subjacente à sua ação é sujeita a mudanças estruturais. Mais do que isso, podemos pensar que a própria incerteza ontológica advém da epistemológica, na medida em que a fonte da mudança estrutural é o comportamento dos agentes econômicos (em particular, os bancos) em meio à ignorância proveniente da falta de informação relevante ${ }^{22}$.

Vejamos melhor o argumento. Como explicado anteriormente, num mundo marcado pela complexidade e limitadas capacidades mentais e computacionais, como o que o Hayek lida, as pessoas fazem uso dos preços como uma fonte de informações sobre o mercado em que atuam. Assim, o sistema de preços funciona como um mecanismo de síntese e transmissão de dados e sinais relevantes para a tomada de decisão por parte dos agentes. A grande "maravilha" do sistema de preços é que ele consegue repassar as informações que de fato são relevantes e de forma simples, sem grande custo para o agente. Poucas pessoas precisam saber o que causou uma mudança nas condições particulares de determinada mercadoria, mas todos os interessados nela recebem o sinal, via mudanças nos preços, de qual deve ser a postura diante dessa mudança, ainda que não venham a saber, na realidade, o que aconteceu. O sistema de preços desempenha, na visão de Hayek, um importante papel cognitivo e, mais especificamente, informativo. Por isso mesmo, ele ajuda a promover a coordenação entre os diversos agentes.

22 Dequech (2004) procura mostrar que as incertezas ontológica e epistemológica podem estar intimamente relacionadas, ao invés de serem entendidas como características totalmente distintas ou até mutuamente exclusivas nos sistemas teóricos que as adotam. 
A questão que se levanta é que não há garantia de que o sistema de preços exerça adequadamente seu papel de transmissor e economizador de informações. Como vimos, a atuação em particular do sistema bancário pode gerar distorções nos preços relativos (em particular, a taxa de juros), de forma que os agentes sejam "enganados" e haja diversos desequilíbrios no sistema econômico. Os bancos atuam de forma incorreta devido à sua incapacidade de terem acesso e articularem satisfatoriamente todas as informações necessárias à correta interpretação da real situação econômica em que estão inseridos.

Isto, porém, não deve ser entendido como uma simples dificuldade de recolher as informações necessárias para o retorno, no período seguinte, ao ponto pré-estabelecido de equilíbrio. O conhecimento necessário à correta atuação dos agentes de modo a trazer a coordenação pelo mecanismo de mercado não era visto por Hayek como disponível, à espera de ser simplesmente coletado pelos agentes durante a etapa de ajustamento à situação anterior à perturbação monetária. Antes, é a própria competição no processo de mercado que faz surgir tal conhecimento, alterando a cada momento os parâmetros da economia, a informação existente e disponível.

O próximo passo da análise hayekiana aqui exposta é admitir que a atuação dos bancos, incompatível com a correta situação econômica subjacente, é a causa de uma mudança no ambiente encarado pelos capitalistas e consumidores. Assim, por exemplo, a oferta excessiva de crédito tende a ocasionar uma onda de investimentos que gera uma alteração na estrutura de capital da economia, alteração esta que pode não ser corroborada por alguma mudança nas preferências intertemporais dos consumidores. Daí a frustração das expectativas e a origem do ciclo econômico. Essa atuação "incorreta" dos bancos é a fonte potencial de transformações no sistema econômico e no cenário enfrentado pelos agentes. A característica dessa mudança estrutural é a inexistência de bases reais acerca de qual o estado que irá prevalecer após o processo de acomodação, durante o qual a economia permanece em desequilíbrio. Como dito no início do artigo, a possibilidade de mudança estrutural, mudança da realidade enfrentada pelos agentes, é a característica distintiva da incerteza fundamental. A nosso juízo, a ação desequilibradora especialmente dos bancos é a fonte dessa mudança estrutural no sistema econômico.

\section{Considerações Finais}

As considerações feitas até aqui apontam que a análise empreendida por Hayek durante os anos 20 e 30 traz implícita a aceitação, pelo austríaco, daquilo que na literatura contemporânea é chamado de incerteza fundamental. Tal 
fato se deve ao papel possivelmente perturbador da moeda dentro do sistema econômico.

A incapacidade de o sistema bancário processar corretamente todas as informações que seriam necessárias o leva a ofertar crédito de modo incompatível com aquela estrutura de capital originada pela taxa de juros, o estado tecnológico e a preferência dos consumidores. Isso provoca uma mudança paramétrica e qualitativa na realidade enfrentada pelos agentes e na informação disponível, característica da incerteza fundamental, onde os estados de mundo prevalecentes e o conhecimento não podem ser trazidos à tona e sequer imaginados anteriormente, não são colocados de antemão aos indivíduos, senão surgem pelos próprios caminhos tomados pelo processo de (re)coordenação do sistema econômico.

Adicionalmente, cumpre-nos ressaltar que, em relação à fase de sua carreira estudada por nós nesse artigo, o programa de pesquisas levado adiante após 1937 pode mostrar mais facilmente como Hayek percebeu a "ignorância radical" do indivíduo vivendo em sociedade. O que Hayek escreveu sobre a natureza subjetiva dos dados utilizados pelos indivíduos e a complexidade do ambiente com que eles se deparam, numa economia em que as decisões são tomadas de forma descentralizada $(1942,1964,1974)$ pode ser associado com o tipo de incerteza que Dequech ( 2006) chama de procedimental. Por outro lado, a visão hayekiana da economia como um processo dinâmico de criação, descoberta e utilização, pelos agentes, de novo conhecimento e de novas oportunidades de ganhos, em oposição à visão estática (ou pelo menos sem incorporar a noção de passagem "real" do tempo) usualmente utilizada pelos seguidores do paradigma neoclássico, traz à luz o tipo de incerteza classificado por Dequech (2000) como fundamental. Ao mesmo tempo, o tratamento dispensado por Hayek à questão do surgimento, mudança e seleção das instituições, vale dizer, sua abordagem evolucionária (não teleológica), traz consigo, também, fortes elementos que permitem afirmar que o austríaco corroborava a visão da economia como um processo permeado pela incerteza fundamental (ANGELI, 2007). Tais considerações, contudo, estão além dos objetivos do presente artigo.

\section{Referências}

ANGELI, E. Hayek e a teoria das Instituições. 2007. 123Fl. Dissertação (Mestrado) - Instituto de Economia, Universidade Estadual de Campinas, Campinas, 2007.

ARIDA, P. Sobre alguns desdobramentos recentes na teoria econômica. São Paulo, 1981. Mimeo.

BARBIERI, F. Filosofia da ciência como ferramenta microeconõmica. Nova Economia, Belo Horizonte, v. 16, n. 3, p. 507-534, 2006. 
BOEHM, S. Austrian economics between the wars: some historiographical problems In: BOEHM, S.; CALDWELL, B. Austrian economics: tensions and new directions. London: Kluwer Academic, 1992. p. 1-30.

BOETTKE P. J. Austrian Institutionalism: a Reply. Research in the History of Economic Thought and Methodology, Bingley, UK, v. 6, p. 181-202, 1989.

BORCH, K. The place of uncertainty in the theories of the Austrian School. In: HICKS, J.; WEBER, W. Carl Menger and the Austrian School of economics. London: Oxford University Press, 1973. p. 61-74.

BURCZAK, T. A. The postmodern moments of F.A. Hayek's economics. Economics and Philosophy, Cambridge, UK, n. 10, n. 1, p. 31-58, 1994.

CALDWELL, B. J. Hayek's transformation. History of Political Economy, Durham, US, v. 20, n. 4, p. 513-541, 1988.

(Org.). Contra Keynes and Cambridge: essays, correspondence. Chicago: University of Chicago Press, 1995. (The Collected Works of F. A. Hayek, 9).

Hayek's challenge: an intellectual biography of F.A. Hayek. Chicago: University of Chicago Press, 2005.

CARVALHO, A. R. Equilíbrio, coordenação e conhecimento: um estudo sobre a questão monetária em Hayek. 2007. 189fl. Dissertação (Mestrado) - Programa de Estudos Pós-Graduados em Economia Política, Pontifícia Universidade Católica de São Paulo, São Paulo, 2007.

CARVALHO, F. J. C. Keynes on probability, uncertainty, and decision making. Journal of Post Keynesian Economics, Armonk, US, v. 11, n. 1, p. 66-99, Sep. 1988.

DEQUECH, D. Uncertainty in a Strong Sense: Meaning and Sources. Economic Issues, Sacramento, US, v. 2, n. 2, p. 221-243, Mar. 1997.

Expectations and confidence under uncertainty. Journal of Post Keynesian Economics, Armonk, US, v. 21, n. 3, p. 415-430, 1999.

. Fundamental uncertainty and ambiguity. Eastern Economic Journal, Bloomsburg, US, v. 26, n. 1, p. 41-60, Winter 2000.

. The New Institutional Economics and the Theory of Behaviour under Uncertainty. Journal of Economic Behavior 8 Organization, Amsterdam, NL v. 59, n. 1, p. 109-131, Jan. 2006.

. Uncertainty: Individuals, Institutions and Technology. Cambridge Journal of Economics, London, UK, v. 28, n. 3, p. 365-378, 2004.

ELLSBERG, D. Risk, Ambiguity and the Savage Axioms. The Quarterly Journal of Economics, Cambridge, US, v. 75, n. 4, p. 643-669, Nov. 1961.

ENDRES, A. M. The origins of Böhm-Bawerk's 'greatest error': theoretical points of separation from Menger. Journal of Institutional and Theoretical Economics, Tubingen, DE, v. 143, n. 2, p. 291-308, Jun. 1987.

FLEETWOOD, S. Hayek's Political Economy: the socio-economics of order. London: Routledge, 1995.

GARRISON, R. W. Time and money: The macroeconomics of capital structure. New York: Routledge, 2001. 
Overconsumption and forced saving in the Mises-Hayek theory of the business cycle. History of Political Economy, Durham, US, v. 36, n. 2, p. 323-349, Summer 2004.

GARRISON, R.; KIRZNER, I. M. Friedrich August von Hayek. In: EATWELL, J.; MILGATE, M.; NEWMAN, P. The New Palgrave: A Dictionary of Economics. London: Macmillan, 1987.

HAYEK, F.A. Monetary theory and the trade cycle. New York: M. Kelley, 1966.

Foreword: On the way In: O'DRISCOLL, G. P. Economics as a coordination problem: the contributions of Friedrich A. Hayek. Kansas City: Sheed Andrews and McMeel, 1977.

Individualism and economic order. Londres: Routledge, 1948a.

1984.

Money, capital and fluctuations: early essays. Chicago: University of Chicago Press,

. New Studies in Philosophy, Politics, Economics and the History of Ideas. London: Melbourne: Routledge: Kegan Paul, 1978.

. Prices and production. Londres: Routledge, 1935.

Price expectations, monetary disturbances and malinvestments. In: Profits, interest and investment: and other essays on the theory of industrial fluctuations. $\overline{2}$. ed. Londres: Routledge E Kegan Paul, [1933] 1950. p. 135-156.

Profits, interest and investment: and other essays on the theory of industrial fluctuations. $2^{\text {nd }}$ ed. London: Routledge: Kegan Paul, 1950. 1967.

Studies in Philosophy, Politics and Economics. Chicago: University of Chicago Press,

.The counter-revolution of science. $2^{\text {nd }}$ ed. Indianapolis: Liberty Press, 1979.

.The pure theory of capital. Chicago: University of Chicago Press, 1975.

HICKS, J. R. Critical essays in monetary theory. Oxford: Clarendon Press, 1967.

HORWITZ, S. Microfoundations and Macroeconomics: An Austrian Perspective. London: Routledge, 2000.

JAFFÉ, W. Menger, Jevons and Walras de-homogeneized In: WALKER, D.A. (Ed.). William Jaffé's essays on Walras. London: Cambridge University Press, 1983. p. 311-342.

KEYNES, J. M. A Treatise on Probability. London: Macmillan, 1921.

. A teoria geral do emprego, do juro e da moeda. São Paulo: Nova Cultural, 1996.

KNIGHT, F. H. Risk, Uncertainty and Profit. New York: Harper E Row, 1957.

KOPPL, R. Austrian economics at the cutting edge. Review of Austrian Economics, v. 19, n. 4 , p. 231-241, 2006.

LAIDLER, D. The price level, relative prices and economic stability: aspects of the interwar debate. BIS Working Papers, n. 136, Set. 2006. Available in: <www.bis.org >. Acessed: 12 dec. 2006.

LEWIS, P. Hayek: From Economics as Equilibrium Analysis to Economics as Social Theory. In: GARRISON, R.; BARRY, N. P. The Elgar Companion to Hayek. Cheltenham: Edward Elgar, 2009. No prelo.

LUCAS JR., R. E. Understanding Business Cycles. In: Studies in Business-Cycle Theory. Cambridge: MIT Press, 1983. 
MISES, L. V. The Theory of Money and Credit. New Haven: Yale University Press, 1953.

. On manipulation of money and credit. New York: Free Market Books, 1978.

MYRDAL, G. Monetary equilibrium. $3^{\text {rd }}$ ed. New York: Sentry Press, 1965.

O'DRISCOLL, G. Economics as a coordination problem. Kansas City: Sheed Andrews and McMeel, 1977.

ROBERTSON, D. H. A moeda. 3. ed. Rio de Janeiro: Zahar, 1969.

SCHUMPETER, J. A. Teoria do desenvolvimento econômico. São Paulo: Nova Cultural, 1996.

SHENOY, S. R. A tiger by the tail: a 40-years' running commentary on Keynesianism by Hayek. London: The Institute of Economic Affairs, 1978.

SOROMENHO, J. E. C. Um estudo sobre as origens da crítica de Hayek ao conceito de equilíbrio. 1994. Tese (Doutorado) - Faculdade de Economia, Administração e Contabilidade, Universidade de São Paulo, São Paulo, 1994.

. Capital e coordenação intertemporal: a visão austríaca. Revista Brasileira de Economia, Rio de Janeiro, v. 52, n. 3, p. 495-522, out. 1998.

SRAFFA, P. Dr. Hayek on money and capital. Economic Journal, Cambridge, US, v. 42, n. 165, p. 42-53, Mar. 1932,

TRAUTWEIN, H. Hayek's double failure in business cycle theory: a note. In: COLONNA, M, HAGEMANN, H. Money and business cycle: the economics of F.A. Hayek. Hants, UK: 1994. V. 1, p. $74-81$.

Recebido em: 07/05/2010.

Aceito em: 05/03/2012. 